\title{
Candidate Genes Polymorphism and Its Association to Prolificacy in Chinese Goats
}

\author{
Yuanqing He (Corresponding author) \\ Institute of Life Sciences, Jiangsu University \\ 301 Xuefu Road, Zhenjiang 212013, China \\ Tel: 86-511-8879-1702 E-mail: yqhe@ujs.edu.cn \\ Xiaoke Ma, Xiaoyong Liu, Cunxia Zhang \& Jun Li \\ Institute of Life Sciences, Jiangsu University \\ 301 Xuefu Road, Zhenjiang 212013, China
}

\begin{abstract}
To find the candidate gene concerned with prolificacy in goats, the most part nucleotide sequence of four genes, including GDF9 gene, BMP15 gene, BMPR1B gene, and INH $\alpha$ gene were identified in three goat breeds for their probable association to the high fecundity. The results showed that none of polymorphism of GDF9 gene, BMP15 gene and BMPR1B gene was tested in goats, and one mutation was detected in INH $\alpha$ gene. The genotype distributions of INH $\alpha$ gene were significantly difference between year-round estrous goat breeds and seasonal estrous goat breeds revealing the association to the prolificacy in goats.
\end{abstract}

Keywords: Goat, PCR-SSCP, Reproduction

\section{Introduction}

The process of ovarian folliculogenesis is composed of proliferation and differentiation of the constitutive cells in developing follicles [Silva et al, 2005]. The number of mature oocytes released during one reproductive cycle and oestrum were determined by a complex exchange of endocrine signals between the pituitary gland and the ovary and by paracrine and possibly autocrine signals within ovarian follicles involving the oocyte and its adjacent somatic cells [Galloway et al., 2000; Eppig, 2001; Durlinger et al., 2002; Knight and Glister, 2003]. In goats, little information is available on the local factors that regulate this process. Many mammals including primates, goats, cattle, deer and possums normally have an ovulation rate of 1 or sometimes 2 whereas other mammals such as rats, mice, hamsters, cats, dogs and pigs have ovulation rates that are between 4 and 15. Current knowledge of major genes for prolificacy in domestic animals falls into three categories: (1) genes where the mutation has been identified and DNA testing is available; (2) genes where the mode of inheritance has been described but the mutation has not been identified; (3) putative genes where there is evidence of apparent genetic segregation but there are insufficient records to ascertain the mode of inheritance [Davis, 2004].

Many years have gone since people have great interest in identification of major genes for prolificacy in ovis aries. In recent years, a number of natural genetic mutations have been identified with ovulation rates varying between 0 and 4 in sheep breeds including one point mutation in the GDF9 gene $\left(\mathrm{FecG}^{\mathrm{H}}\right)$, five different mutations in the bone morphogenetic protein 15 gene $\left(F e c X^{\mathrm{G}}, \mathrm{FecX}^{\mathrm{B}}, \mathrm{FecX}^{\mathrm{I}}, \mathrm{FecX}^{\mathrm{H}}, \mathrm{FecX} \mathrm{X}^{\mathrm{L}}\right)$, and one in the BMPR1B gene (FecB). It was certificated that these mutations had great association to the ovulation rate of different sheep breeds, especially the Fec $\mathrm{B}$ mutation (Booroola breed) and $\mathrm{Fec} \mathrm{X}^{\mathrm{G}}$ (Inverdale breed). In the present study, these genes were selected again to detect the probably effects on goat prolificacy.

Inhibin, a glycoprotein, is a gonadal hormone, which can inhibit the synthesis and secretion of pituitary follicle-stimulating hormone (FSH), which has an important role in the recruitment and development of ovarian follicles during the folliculogenesis, and Ala257Thr missense mutation of INH $\alpha$ gene, has an important role of its receptor binding, and has been indicated as candidate gene in premature ovarian failure (POF) pathogenesis. Therefore, the INH $\alpha$ gene was selected as the fourth candidate gene. We investigated the single nucleotide polymorphism (SNP) of the four genes in goat breeds by single strand conformation polymorphism (SSCP) method, and discuss the association to the reproductive traits in goats. 


\section{Materials and methods}

\subsection{Animal samples and DNA extraction}

All the samples were collected in china. 170 Haimen goats were collected from haimen goat conservation base located in haimen city of Jiangsu province, 80 Boer goats and 40 huanghui goats were collected from Boer reproductive base located in feng city in Jiangsu province. Ovulatory activity of most goat breeds in generally inhibited for several consecutive months of the year, referred to as the anestrous seasonality, which occurs during the spring and summer. However, Haimen goat, which was an excellent local breed in China, displays significant characteristics of year-round estrus and higher average litter size. The other goat breeds in this study display significant characteristics of seasonal estrus [Tu, 1989]. These does were chosen at random. Genomic DNA was extracted from whole blood by phenol-chloroform method, and then dissolved in TE buffer (10mmol/1 Tris-HCl (PH 8.0), 1mmol/1 EDTA (PH 8.0)) and kept at $-20^{\circ} \mathrm{C}$

\subsection{Single-stranded conformation polymorphism (SSCP) for genes}

Primers were designed from nucleotide sequence GenBank accession number AF078545(GDF9), AF236078(BMP15 exon1), AF236079(BMP15 exon2), AF357007 (BMPR1B), BTU16237(INH $\alpha$ ). The polymerase chain reaction were carried out as follows: denaturation at $94^{\circ} \mathrm{C}$ for $5 \mathrm{~min}$, followed by 33 cycles of denaturation at $94^{\circ} \mathrm{C}$ for $40 \mathrm{sec}$, annealing at different temperature and different time by the primer, extension at $72^{\circ} \mathrm{C}$ for $40 \mathrm{sec}$, with a final extension at $72^{\circ} \mathrm{C}$ for $10 \mathrm{~min}$ on Mastercycler 5333 (Eppendorf AG, Hamburg, Germany). The PCR products were heated to $95^{\circ} \mathrm{C}$ for $5 \mathrm{~min}$ to denature the samples, and immediately placed on ice to prevent DNA strands from reannealing. A $3 \mu \mathrm{l}$ aliquot of each sample was electrophoresed overnight at 200-300 V. The SSCP gels consisted of 0.5 $\times$ Tris-borate-EDTA (TBE) buffer, $8 \%$ or $10 \%$ or $12 \%$ polyacrylamide, $5 \%$ glycerol, $10 \mu \mathrm{l}(25 \% \mathrm{w} / \mathrm{v})$ ammonium persulphate and $10 \mu \mathrm{l}$, $\mathrm{N}$, $\mathrm{N}^{\prime}$, N-tetramethylethylenedia-mine (TEMED) for every $10 \mathrm{ml}$ of nondenaturing gel. Electrophoresis was performed at low temperature $\left(4^{\circ} \mathrm{C}\right)$, using $0.5 \times \mathrm{TBE}$ running buffer. The DNA was visualized using silver staining.

\subsection{Cloning and sequencing}

PCR products were separated on 1.0\% agarose gels and re-extracted using Gene clean II kit (Promega, Madison, WI USA). Each DNA fragment was ligated into the pGEM-T Easy vector (Promega, Madison, WI USA) at $16^{\circ} \mathrm{C}$ overnight according to the manufacturer's instructions. The ligation reactions were carried out in $10 \mu \mathrm{l}$ volume containing PCR product $1 \mu \mathrm{l}$, pGEM-T easy vector $(50 \mathrm{ng} / \mu \mathrm{l}) 1 \mu \mathrm{l}$, T4 ligase $(3 \mathrm{U} / \mu \mathrm{l}) 1 \mu \mathrm{l}, 2 \times$ ligation buffer $5 \mu \mathrm{l}$, ddH2O $2 \mu \mathrm{l}$. Each DNA fragment was then transformed into Escherichia coli DH5 $\alpha$ competence cell. Positive clones of transformed cells were identified by restriction enzyme digestion. Two clones of each genotype were selected and sequenced. Each clone was sequenced for twice. The target DNA fragments in recombinant plasmids were sequenced from both directions using an automatic ABI 377 sequencer (Perkin Elmer Applied Biosystems, Forster City, CA, USA) by Shanghai Sangon Biotechnological Engineering Technololgy\&Services Co.Ltd. (Shanghai, China).

\subsection{Statistical analysis}

Distribution of genotypes between different goat breeds was analyzed using chi-square method.

\section{Results}

\subsection{SSCP analysis of four genes}

Primer pairs were used to amplify genomic DNA of different genes, and the PCR products were separated on $1.5 \%$ agarose gels. The results showed that amplication products had good specificity, which could be directly analyzed by SSCP. The PCR products were electrophoresed overnight and visualized by silver staining. The results showed the primers of BMP15 gene, GDF9 gene and BMPR1B gene had no polymorphism (figure 1), and the primers of INH $\alpha$ gene showed different genotypes (figure 2).

\subsection{Sequencing of different genotypes}

In this study, we did not find any mutation in GDF9 gene, BMP15 gene and BMPR1B gene, and find a mutation in INH $\alpha$ gene resulting different bandtype and sequence difference, it was C865T (figure 3). The C865T mutation existed in the exon of INH $\alpha$ gene, and did not induce an amino acid change and was silent. Sequence alignment indicated that the homology of 884bp nucleotides of 5'-flanking sequence and exon of caprine INH $\alpha$ gene between this study and Bos Taurus gene (BTU16237) in GenBank was 98.2\%, and the homology of exon and deduced amino acid sequence was $97 \%$ and $98 \%$ respectively.

\subsection{Allele and genotype frequencies of INHa gene in different goat breeds}

Allele and genotype frequencies of exon of INH $\alpha$ gene in different goat breeds were shown in Table 1. For this mutation, the distribution of gene frequency in Haimen goats was obviously different from the other goat breeds, and the bb genotype was also higher than the other goat breeds significantly, which means that the frequency of genotype bb was obviously higher in year-round estrous goat breeds than in seasonal estrous goat breeds. These results preliminarily 
showed an association between genotype bb and year-round estrus in goats.

\subsection{Chi-square analysis for INHa genotype distribution in different goat breeds}

We also analyzed the genotype distribution by chi-square method, and the test result was summarized in Table 2. For C865T mutation, the differences of genotype distributions were significant $(\mathrm{P}<0.001)$ between Haimen goats and the other goat breeds, which also means that the difference of genotype distributions were significant between year-round estrous goat breeds and seasonal estrous goat breeds. Furthermore, the difference of genotype distributions were not significant $(\mathrm{P}=0.11>0.05)$ between Boer goats and Huanghuai goats.

\section{Discussion}

DNA tests are the key to the utilization of these genes in the sheep industry and have also been a useful tool for determining the genetic basis of high prolificacy in distantly related breeds around the world. A variety of inheritance patterns are associated with these genes and there is a wide range in the size of the effect on ovulation rate. Artificial insemination and embryo transfer programmes have been used to successfully introgress the Booroola and Inverdale genes into other breeds in several countries, and these artificial breeding technologies have been particularly useful while only small numbers of progeny tested individuals have been available [Davis, 2004]. The goat breeding is just like the sheep, we also need to find out the key mutations in the candidate genes and know how these mutations affect the reproduction and how to increase the reproductive capability including reproductive seasonality and litter size, which will be a rapid and economic method to improve the goat breeding speed.

GDF9, BMP15, and BMPR1B gene enhanced the primary and preantral follicular growth in vitro and in vivo, and expressed in all the stages of the normal ovarian follicle development [Hayashi et al, 1999; Vitt et al, 2000; Hanrahan et al, 2004]. These genes were detected increasing ovulation in sheep breeds, especially $\mathrm{FecG}^{\mathrm{H}}$ mutation of GDF9 gene in Belcare and cambridge breeds, $\mathrm{FeCX}^{\mathrm{G}}, \mathrm{Fecx}^{\mathrm{B}}, \mathrm{Fecx}^{\mathrm{I}}, \mathrm{Fecx}^{\mathrm{H}}$ and $\mathrm{Fecx}^{\mathrm{L}}$ mutation of BMP15 gene in several sheep breeds, and FecB mutation in BMPR1B gene[Davis et al, 2006]. In the present study, the results indicated that none of these mutations can be detected in all goat breeds including the high fecundity and low fecundity goat breeds, these mutations had no obviously effect on the difference of prolificacy in goats. They cannot be regarded as the major gene associated with the fecundity of goats. This conclusion also agrees with another research in Chinese [Hua, et al, 2008].

$\mathrm{INH} \alpha$ gene was also detected in all individuals as the candidate gene. Recent years many studies on human research indicated that INH $\alpha$ gene was a strong candidate gene for premature ovarian failure (POF) [Harris et al., 2005; Munz et al., 2004]. They found the Ala257Thr missense mutation in INH $\alpha$ gene with high statistical significance in POF (9 out of $80,11.2 \%$ ) (Fisher's exact test, $\mathrm{P}=0.0005$ ), and the conclusion was the $\mathrm{INH} \alpha$ gene is a strong candidate gene for ovarian failure [Dixit et al., 2004]. Other studies showed that INH $\alpha$ gene had the significant additive effect on the sheep prolificacy, INHA, INHBA, and INHBB had obviously gene effect on litter size [Jaeger, et al, 1994; Hiendleder, et al, 1996; Hiendleder, et al, 2002]. Another study showed that INH $\alpha$ gene had TaqI restriction fragment length polymorphism (RFLP), and TaqI A allele associated to the average litter size on sheep breed [Leyhe, et al, 1994; Sise, et al,1991]. In this study, we found a mutation (C865T) for the first time existed in the exon of the gene, which made an obviously difference in the gene frequency and the genotype frequency between the year-round estrous goat breed and the seasonal estrous goat breeds. We had known that inhibin gene is a completely conserved gene, and any mutation maybe lead to the functional decrease or failure. To certificate the difference of three goat breeds, we applied the Chi-square method to analyze the genotype distribution. The results presented that the differences of genotype distributions were significant $(\mathrm{P}<0.001)$ between Haimen goats and the other goat breeds, which also showed that the difference of genotype distributions were significant between year-round estrous goat breed and seasonal estrous goat breeds. According to these results, we concluded that INH $\alpha$ gene can be regarded as a candidate gene of goat high prolificacy.

\section{Acknowledgments}

This work was supported by Jiangsu Natural Science Foundation of China (No.BK2007561) and Jiangsu University Foundation of China (No.07JDG16).

\section{References}

Davis et al. (2006). Investigation of the Booroola ( $\mathrm{FecB})$ and Inverdale (FecX $\mathrm{X}^{\mathrm{I}}$ mutations in 21 prolific breeds and strains of sheep sampled in 13 countries. Anim. Reprod. Sci., 92, 87-96.

Davis G. H. (2004). Fecundity genes in sheep. Anim. Reprod. Sci., 82, 247-253.

Dixit et al. (2004). Mutational analysis of the mature peptide region of inhibin genes in Indian women with ovarian failure. Hum Reprod., 19(8):1760-1764.

Durlinger, et al. (2002). Regulation of ovarian function: the role of anti-Mullerian hormone. Reproduction, 124, 601-609. 
Eppig, J.J. (2001). Oocyte control of ovarian follicular development and function in mammals. Reproduction, 122, 829-838.

Galloway et al. (2000). Mutations in an oocyte-derived growth factor gene (BMP15) cause increased ovulation rate and infertility in a dosage-sensitive manner. Nat. Genet., 25, 279-283.

Hanrahan, et al. (2004). Mutations in the genes for oocyte derived growth factors GDF9 and BMP15 are associated with both increased ovulation rate and sterility in Cambridge and Belclare sheep (Ovis aries), Biol. Reprod., 70, 900-909.

Harris et al. (2005). INH $\alpha$ promoter polymorphisms are associated with premature ovarian failure. Mol Hum Reprod., 11(11):779-784.

Hayashi et al. (1999). Recombinant growth differentiation factor-9 (GDF9) enhances growth and differentiation of cultured early ovarian follicles. Endocrinology, 140:1236-1244.

Hiendleder et al. (1996). Genomic cloning and comparative sequence analysis of different alleles of the ovine $\beta A$-inhibin/activin (INHBA) genes as a potential QTL for litter size. Animal genetics, 27(suppl.2):119.

Hiendleder. (2002). Nucleotide sequence of ovine $\alpha$-inhibin (INHA) genes and evaluation of RFLP marker effects on reproductive performance. Animal Genetics, 33(3)247-248.

Hua et al. (2008). None of polymorphism of ovine fecundity major genes FecB and FecX was tested in goat. Ani. Reprod. Sci., 108:279-286.

Jaeger et al. (1994). Cosmid cloning and characterization of the coding regions and regulatory elements of the ovine $\alpha$-(INHA), $\beta$ A-(INHBA) and $\beta$ B-inhibin (INHBB) genes. Animal genetics, 25(suppl.2):33.

Knight et al. (2003). Local roles of TGF $\beta$ - superfamily members in the control of ovarian follicular development. Anim. Reprod. Sci., 78, 165-183.

Leyhe et al. (1994). Pronounced differences in the frequency Taq I $\beta_{\mathrm{A}}$ inhibin alleles between sheep breeds with different reproductive performance. Animal Genetics, 25(1):41-43.

Munz et al. (2004). Serum inhibin A, inhibin B, pro-alphaC, and activin A levels in women with idiopathic premature ovarian failure. Fertil Steril., 82 (3):760-762.

Silva et al. (2005). Expression of growth differentiation factor 9 (GDF9), bone morphogenetic protein 15 (BMP15), and BMP receptors in the ovaries of goats. Mol. Reprod. Dev., 70:11-19.

Sise et al. (1991). A Taq I polymorphism at the ovine $\alpha$-inhibin locus. Animal Genetics, 22(2):195.

Tu, Y. R. (1989). The Sheep and Goat Breeds in China. Shanghai Science and Technology Press, Shanghai, P.R. China.

Vitt et al. (2000). In vivo treatment with GDF9 stimulates primordial and primary follicle progression and theca cell marker CYP17 in ovaries of immature rats. Endocrinology, 141:3814-3820.

\section{Note}

Abbreviations: GDF9 gene, Growth differentiation factor-9 gene; BMP15 gene, bone morphogenetic protein 15 gene; BMPR1B gene, bone morphogenetic protein receptor $1 \mathrm{~B}$; INH $\alpha$ gene, inhibin $\alpha$ gene.

Table 1. Gene frequency and genotype frequency of the INH $\alpha$ gene in goat breeds

\begin{tabular}{|c|c|c|c|c|c|c|}
\hline \multirow{2}{*}{ Breed } & \multirow{2}{*}{ No. } & \multicolumn{2}{|c|}{ Gene frequency } & \multicolumn{3}{|c|}{ Genotype frequency } \\
\hline & & $B$ & $b$ & $B B$ & $B b$ & $b b$ \\
\hline Haimen goats & 170 & 0.04 & 0.96 & $\begin{array}{c}0 \\
(0)\end{array}$ & $\begin{array}{l}0.08 \\
(14)\end{array}$ & $\begin{array}{c}0.92 \\
(156)\end{array}$ \\
\hline Boer goats & 80 & 0.44 & 0.56 & $\begin{array}{c}0 \\
(0)\end{array}$ & $\begin{array}{l}0.84 \\
(67)\end{array}$ & $\begin{array}{l}0.16 \\
(13)\end{array}$ \\
\hline Huanghuai goats & 40 & 0.39 & 0.61 & $\begin{array}{c}0.02 \\
(1)\end{array}$ & $\begin{array}{l}0.70 \\
(28)\end{array}$ & $\begin{array}{l}0.28 \\
(11)\end{array}$ \\
\hline
\end{tabular}

Note: the numbers in the brackets are the genotype individuals. 
Table 2. Chi-square testing of genotype distributions of INH $\alpha$ gene in goat breeds

\begin{tabular}{ccc|}
\hline breed & Boer goats & Huanghuai goats \\
\hline Haimen goats & $141.64 * * *$ & $82.83 * * *$ \\
Boer goats & & 4.32 \\
\hline
\end{tabular}

$* P<0.05, \quad * * P<0.01, \quad * * * P<0.001$

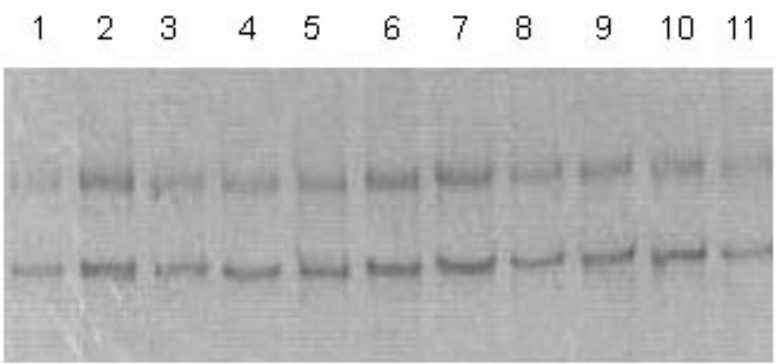

Fig.1 SSCP results of GDF9 gene, BMP15 gene and BMPR1B gene(simplex bandtype)

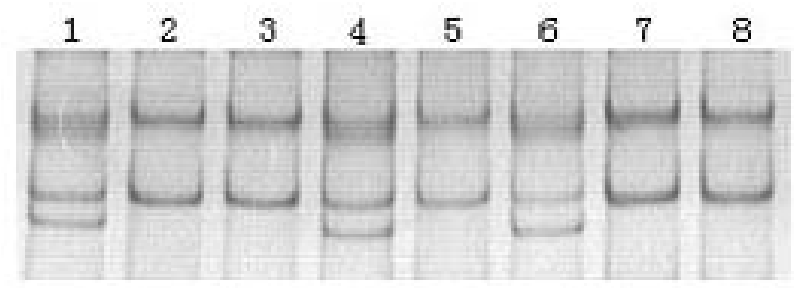

Fig.2 SSCP results of INHo gene(polymomhic bandtype)

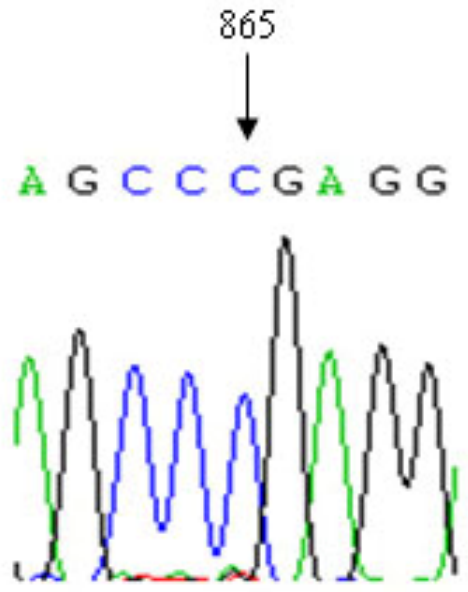

(bb genotype)

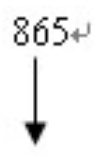

$\AA G C C T G A G G$

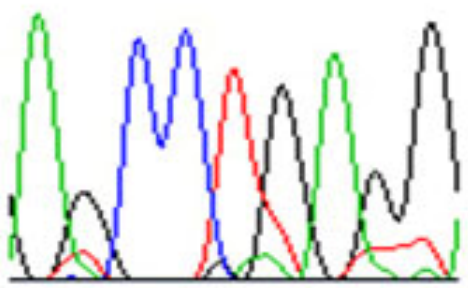

(Bb genotype)

Fig. 3 Sequence comparison of bb and Bb genotypes at $865 \mathrm{bp}$ of INH $\alpha$ gene in goats 